\title{
The Application of Folk New Year Paintings in the Character Design of Chinese Animation
}

\author{
Jindong Wang \\ Fijian Jiangxia University, Fuzhou 350002, China. \\ wjdpm2008@163.com
}

\begin{abstract}
Keywords: Folk new year paintings; Character figures; Chinese animation; Role design
\end{abstract}
\begin{abstract}
Folk New Year paintings are an important part of traditional Chinese culture, reflecting customs, thoughts and aesthetic spirits of working people. Pass on around millennium, but disappears in the cultural life of modern society. The serious deficiency is undoubtedly a great loss and regret in the traditional culture of modern society. Although folk paintings in modern life are almost hard to trace, the culture and spirit connotation still arouse people's nation identity in traditional culture. So it is important that analysis the influence of Folk New Year paintings and traditional Chinese animation - In this context, Analysis the influence of traditional Chinese animation to compare the "meaning","shape","color", and the value of the creation in traditional Chinese animation and Folk New Year paintings. it is important that for the Chinese traditional culture to develop in the new age.
\end{abstract}

\section{Introduction}

Folk New Year paintings is not only a form of folk art, but is the expression of national aesthetic mind and popularity of thoughts and feelings. The popularity genes represent aesthetic spirits of a nation, in turn, the spirits expresses Chinese art features in animation works. Looking back classic Chinese animation, we find traditional culture has its unique nation charm. It is the quality of modern Chinese animations that are missing.

Between 1850s and 1880s, Chinese animation creates a large number of works with strong ethnic characteristics from absorbing nutrients in folk New Year paintings. Those animation works get many awards in various international movies and animation festivals. Chinese animation enters the most glorious period in history with setting off a "Chinese School" wind in international animation field. However, the glory of Chinese animation quickly falls into a trough with the opening of animation market. America and Japan quickly capture the Chinese animation market. These animation powers have unique national styles, improved production system and mature business operation models. Up to now, Chinese animation generally follows the step of America and Japan. Without national culture foundation, Chinese animation not only loses domestic market, but the possibility into international market. Therefore, the only way to arise Chinese animation is to combine folk New Year paintings with unique national culture essence and advanced creative thinking and technology in foreign countries. That is where the significance of folk New Year paintings lies.

\section{The Inheritance of Meaning}

"Shuowen Jiezi": "meaning means ambition." "Meaning" refers to the human thoughts, ideas and other hidden spiritual culture. In the folk New Year paintings contain a number of recessive spirit culture[1].Folk New Year paintings are the art of labor masses both in content and form. They directly reflect the working people's thoughts, feelings and aesthetic spirits. The creation of folk artists will not be rigidly adhered to the creation rules of official art, but by virtue of nature and insights of life with a natural instinct. They are applied to the expression of sincere inner feelings, drawing on local materials, making the best of existing facilities, seizing main features and spiritual qualities of an object with bold exaggeration, distortion and reconstruction, creating an unique and simple artistic qualities [2]. Just as what Zuo Hanzhong says in Chinese Folk Art Sculpts:" Folk artists' creation is focused on straightforward expression of inner sentiments. When they portray figures, they recreate and modify the impression according to their own minds and objectives instead of direct copy of 
visual impression. In shaping figures, folk artists tend to recapitulatively show nature and essence of images according to circumstances [3]."

Chinese animation borrows pure and natural intension of folk New Year paintings. Nezha Conquers the Dragon King is a typical example. Nezha's birth scene is in the middle of a lotus, which is from a folk New Year picture "best wishes on a new baby". The auspicious meaning is the deconstruction of non-stationary object. In the design of Nezha's rebirth, the film uses fire and water to symbolize "hope" and "life". When Nezha and his master meet, the film specially designs a rare 360 ' rotating scene. Such shots bring the audience's emotions into the climax, exaggerating the hero image of $\mathrm{Na}$ Zha's rebirth as well as reflecting his kindness. Meanwhile, the film is increased to a new height. 360 degree rotation is a "circle", which symbolizes the fullness of Nezha' rebirth, making him full of human nature. The figure of Fairy Primordial (Tai Yi) is captured smartly. He celestially rides the crane with white hair and kind face. When Li Jing flatters him as fairy, Tai Yi says:" the fairy also comes from human beings, but humans are not determined. I am just an old joker man and take up the cudgels against the injustice. What he says clearly reveals the pure and ideal inner world of Chinese people. The design of Tai Yi is from the affirmation of reality and the expectation of happiness. Just as Director Ada says, The formation of the national style of a film is the result of harmonious unity of various factors, rather than the use of a bit national flavor in some details, props or costumes. Obviously, a real national animation needs a deeper understanding of nation spirit.

\section{The Recreation of Figures}

Xu Shen "Shuowen Jiezi": "shape means pictographic." "The book of changes, copulative" contains: "Manufacturing image in heaven, Shaping in earth." It means that the shape is visible, visible, and concrete. In the reality of art creation, "shape" (Manufacturing) is the external manifestation of "meaning" (Design), the folk New Year pictures is conception of a folk artists.Most authors of folk New Year paintings come from the bottom of working people, neither of high education nor of book knowledge. They form their own methods and aesthetic standards of creation through "secrets" and "patterns" passes on from generation to generation. Folk authors have strict stylized figure rules, such as the painting of door-god Qin Qiong and Yuchi Jingde. Their modeling come from Tang Dynasty and are kept till today. The biggest feature of door-god paintings perform in two aspects--- "shaping figure" and "shaping power". In "shaping figure", the emphasis is laid on stout-body, complete layout and facial features. In "shaping power", internal potential is focused on, which is adapted to door structure and creates an atmosphere of dignity. Dashing face and dignified armor give people a strong visual impact and sense of dignity. Flying beard and streamer make the static figure full of vigor. The door-gods' features have been an unchangeable standard figure, "although geographical differences may exist." The whip may be on the horse or between legs and the ancient weapons may be hammer, axe or mace [4]. There are loads of stylized figures such as "doll-like"," lady-like, "God-like" and so on. They all have a "secret" for reference.

Image carrier of animation expressive language which needs individuation is different from stylized paintings. "Individuation" is the primary factor in shaping characters personalities, which is the visual image carrier to impress the audience and put forward animation, above all, the key to animation success. The first multi-colored animation "Why Is A Raven Black" in China in 1956 won the award of the Seventh International Children's Film Festival in Venice. Although it gains recognition of the international animation industry, it is mistakenly regarded as works in Soviet Union due to the lack of national characteristics. The animation makers at that time have a deep reflection. Tewei, as the representative of a group of artists, carves out a new situation that is to "knock the door of comedy; start the national characteristics". They make China's first animation "Proud General" with national characteristics, the Hero of which is based on door-god folk New Year paintings. He has a small build with a big head, both majestic and charmingly naive. The vivid image of an arrogant and defeated ancient general is presented. In the animation "The Monkey King", the image of the Jade Emperor takes features of Kitchen God and the God of wealth. The Jade Emperor has loose fat face, drooping pouch, slender fingers, fair skin, cheeks with light cosmetics, appearing 
as a solemn and peaceful man. When he is angry, he shows wickedness by lifting up eyebrows. Only one glance may reveal he is extremely conceited and enjoying fortune and honor. The hypocrisy and piquant character is vividly captured [5]. In the paper-cut film "Baby Ginseng"( refer with: Fig. 1, Fig. 2), it borrows the painting figure Fuwa, wearing a small bellyband. Thus, it is the stylized New Year paintings that give Chinese animation strong national characteristics.

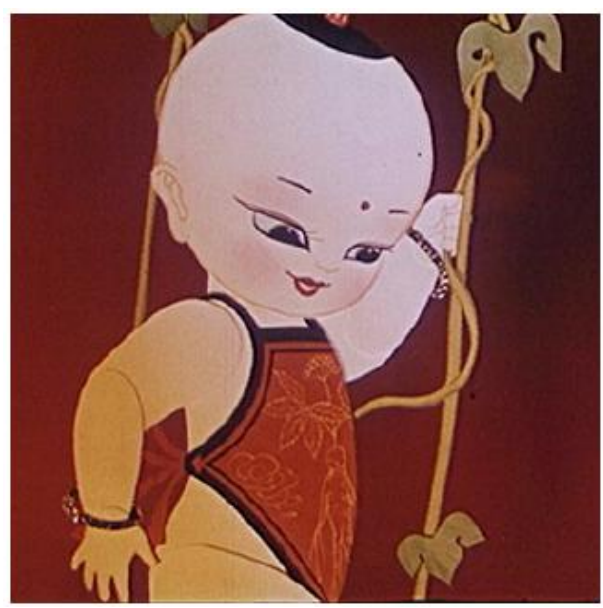

Figure 1. Paper cutting animation "ginseng Doll"

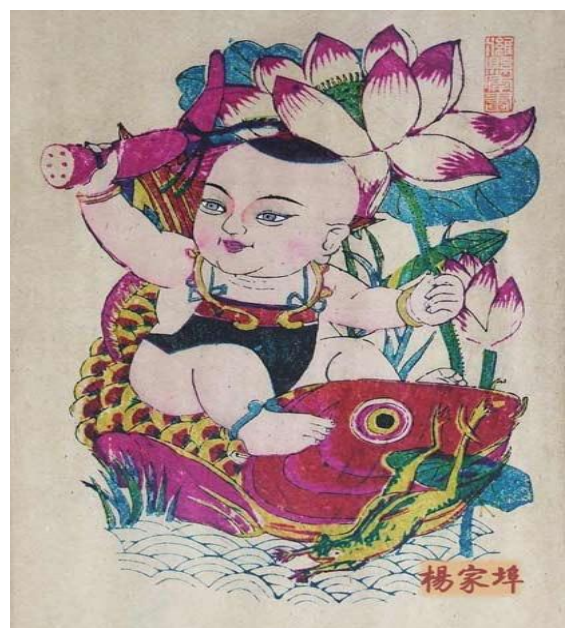

Figure 2. Yangjiabu New Year paintings

\section{The Extension of Color}

"Shang Shu Yi Ji":To reflect the colorful wourld in five colors. The "Five Colors" are green, yellow, red, white and black, which correspond with traditional Chinese philosophy and thoughts. In the thousands of years of inheritance, the special aesthetic views of Chinese come into being, which has a profound impact on Chinese color view[6]. The colors of Folk New Year paintings are neither the description and copy of true color nor the artistic feeling of painting makers, but the unique color system based on traditional Chinese "Five Colors", which are from the aesthetic requirements in people's daily life and folk activities to pray for auspices. Colors in folk pictures go beyond the color representation of objects in real life situation, which has the symbolic significance of primitive life consciousness and auspices. For instance, peach red symbolizes happiness and joy in the folk, so there is always peach red in "doll-like", "Lady-like", "civilian-like" and even "generals". This color portrays the inner world of people yearning for good luck and happiness. Folk paintings use a number of primary colors, especially collocation of complementary colors like yellow with red and red with green, which have strong contrast and distinct jumps. such color-matching enhance the visual impact and give people a warm, cheerful and happy inner sense[7]. The secrets of Yangjiabu color formula is "Purple bones, green tendon, with red and yellow contributing to a new master; red means newness and yellow light, too much green is too bad. Purple hair to evil yellow hair pooh, with a clean paint drawing bright; red and yellow is jubilant while red and purple is smelly and vulgar[8]." These color secrets represent the majority of working people give colors different personality traits in the long-term folk activities and labor practice, which are deeply implanted in people's mental world and contribute to the formation of unique color system in the folk New Year paintings.

Color design of roles is not only a symbol of character's personality, preferences, identity, status, good and evil, but the different cultural background. Color design and the intention color system in the folk New Year paintings can be traced to the same origin. In animation "The Monkey King", the roles' color design take references from folk paintings, with loads of red, green and purple colors. For instance, Sun Wukong has green eyebrows, red face, yellow robe jacket, red pants, bluish green scarf, and a pair of black boots, which are all bright colors. His "yellow robe" better reflects his resistance, highlighting the theme and connotation of the film[9]. Red is a symbol of passion, enthusiasm, vigor, force, and anger. In traditional culture, red stands for good luck and happiness. Red in Sun Wukong shows he is full of vitality, optimist and energy. Green scarf is a shining spot that symbolizes life, 
hope and vitality, justice and honesty. The choice of green scarf makes a sharp contrast to his clothes and echoes with his facial color, which has a bright, warm and relaxed effect, emphasizing contrasts well as harmony and unity[10]. Color system in folk pictures is applied in this film, giving Chinese animation distinct national characteristics, which enhances visual effect and gains culture recognition.

\section{Conclusion}

When the actual environment that folk paintings rely on gradually disappears, the inheritance and protection of folk paintings cannot be limited to the old concepts. The intrinsic thinking should be broken through. The "essence" of folk paintings should be inherited through new language forms and media, which expand the visual form of folk New Year paintings and promote the national development of Chinese animation. Of course, the nationalization of Chinese animation must not be a copy of "Chinese School". Instead, the essence of folk paintings as well as the creation concepts and technology should be combined, hence making excellent animation works that have unique national features and international quality. Only in this way can Chinese animation recover vitality and splendor. The vanishing of folk New Year paintings can regain new life and be passed on.

\section{References}

[1] Y.H. Li: The Application of Chinese Cultural Symbols in the Design of Animation Role -- Based on the Aesthetic Category of Intention. Journal of Shenzhen University (HUMANITIES AND SOCIAL SCIENCES) twenty-ninth-volumes, Vol.29 (2012)No.5, p.75.

[2] Z.H. Yang : Analysis the of Beauty in the Factors Influence on Traditional Forms of a Woodcut New Year paintings: as an Example of Zhuxianzhen New Year Paintings. "decoration" (2013)No.12,p.43.

[3] H.Z.Zuo: Chinese Folk Art Sculpts ( Hunan Fine Art Press, Chinese 2006), p.255.

[4] H.Z.Zuo: Chinese Folk Art Sculpts ( Hunan Fine Art Press, Chinese 2006), p.255.

[5] Z.W..Xu and S.J.Liu : Review the Modernizing Modeling From Chinese Animation "havoc in heaven" . "Film review" (2006 )No.14,p.34.

[6] S.J.Liu: Analysis the Features of Woodcut Woodcut New Year Paintings in Huaxian and Zhuxianzhen"decoration" (2010)No.8,p.65.

[7] Y. Yan: The Application of "zhuo" in the Perspective of Folk Art which in the Children's Picture Books" decoration" (2013)No.2,p.62.

[8] S.C.Wang: History of Chinese Folk Art(Guangzhou Lingnan Fine Art Press, Chinese 2004), p.46.

[9] Z.W..Xu and S.J.Liu : Review the Modernizing Modeling From Chinese Animation "havoc in heaven" . "Film review" (2006 )No.14,p.35.

[10]Z.W..Xu and S.J.Liu : Review the Modernizing Modeling From Chinese Animation "havoc in heaven" . "Film review"(2006 )No.14,p.36. 